Check for updates

Cite this: Mater. Chem. Front. 2019, 3, 1317

Received 16th January 2019, Accepted 9th March 2019

DOI: $10.1039 / c 9 q m 00024 k$

rsc.li/frontiers-materials

\title{
A sandwich-type sulfur cathode based on multifunctional ceria hollow spheres for high-performance lithium-sulfur batteries $\dagger$
}

\author{
Jianwei Wang, ${ }^{\text {ab }}$ Bo Zhou, (D) C Hongyang Zhao, ${ }^{\mathrm{b}}$ Miaomiao Wu, ${ }^{\mathrm{b}}$ Yaodong Yang, ${ }^{\mathrm{b}}$ \\ Xiaolei Sun, ${ }^{a}$ Donghai Wang ${ }^{d}$ and Yaping Du (D) *ab
}

\begin{abstract}
Despite prominent research efforts towards developing cathode materials for lithium-sulfur batteries, relatively little emphasis has been placed on constructing functional cathode architectures. Herein, ceria $\left(\mathrm{CeO}_{2}\right)$ hollow spheres are prepared to fabricate the inside and outside structures of cathodes. A sandwich-type sulfur cathode, namely, a $h-\mathrm{CeO}_{2} /$ sulfur $-x-\mathrm{CNT} / \mathrm{h}-\mathrm{CeO}_{2}$ cathode, is designed and fabricated by a simple layer-by-layer process. Due to its unique structural and compositional features, the $\mathrm{h}-\mathrm{CeO}_{2} /$ sulfur-0.8-CNT/h- $\mathrm{CeO}_{2}$ cathode delivers high specific capacities of 876,761 , and $644 \mathrm{~mA} \mathrm{~h} \mathrm{~g}$ at $1 \mathrm{C}, 2 \mathrm{C}$ and $5 \mathrm{C}$ rates, and the capacity retentions are $85.7 \%, 87.8 \%$, and $92.4 \%$, respectively. During 100 test cycles, the material displays high coulombic efficiencies (above 99\%) after the first cycle. More importantly, the cathode with a sulfur loading of $1.8 \mathrm{mg} \mathrm{cm}^{-2}$ also exhibits a stable cycling life up to 500 cycles at $1 \mathrm{C}$ with a capacity decay as low as $0.073 \%$ per cycle.
\end{abstract}

\section{Introduction}

The requirement for the rapid development of advanced energy storage systems has intensified worldwide the focus on lithium-sulfur ( $\mathrm{Li}-\mathrm{S}$ ) batteries, due to their high theoretical capacity (1672 $\mathrm{mA} \mathrm{h} \mathrm{g}^{-1}$ ) and energy density $\left(2600 \mathrm{~W} \mathrm{~h} \mathrm{~kg}^{-1}\right){ }^{1-3}$ Compared to currently used cathode materials, sulfur has the advantages of natural abundance (260 ppm in the earth's crust), low cost ( $\left.\$ 0.15 \mathrm{~kg}^{-1}\right)$, and environmental benignity. ${ }^{4-6}$ $\mathrm{Li}-\mathrm{S}$ batteries are considered to be one of the most promising candidates for next-generation high energy storage devices. ${ }^{7,8}$ In spite of their great achievements in recent years, several obstacles to their commercialization still exist: ${ }^{9,10}$ (a) the poor electrical conductivity of sulfur $\left(5 \times 10^{-30} \mathrm{~S} \mathrm{~cm}^{-1}\right)$ and the discharge products $\left(\mathrm{Li}_{2} \mathrm{~S}_{2} / \mathrm{Li}_{2} \mathrm{~S}\right),(\mathrm{b})$ the large volume expansion

\footnotetext{
${ }^{a}$ School of Materials Science and Engineering \& National Institute for Advanced Materials, Tianjin Key Lab for Rare Earth Materials and Applications,

Centre for Rare Earth and Inorganic Functional Materials, Nankai University, Tianjin 300350, China. E-mail: ypdu@nankai.edu.cn

${ }^{b}$ Frontier Institute of Science and Technology, Xi'an Jiaotong University, Xi'an 710054, China

${ }^{c}$ Institute of Modern Physics, Shaanxi Key Laboratory for Theoretical Physics Frontiers, Northwest University, Xi'an 710069, China

${ }^{d}$ Department of Mechanical and Nuclear Engineering, Pennsylvania State University, University Park, PA 16802, USA

$\dagger$ Electronic supplementary information (ESI) available: Preparation of materials, electrochemical and structure characterization, computational method, optimized geometries, and schematic illustration of the cathode configuration. See DOI: 10.1039/c9qm00024k
}

upon lithiation $(\sim 80 \%$, which would inevitably cause collapse of the electrode structure), (c) the sluggish kinetics of polysulfide redox reactions, (d) the high solubility and diffusion of intermediate lithium polysulfides in organic electrolytes (which would lead to irreversible loss of active materials, rapid capacity fading and low coulombic efficiency), and (e) the low electrode loading and low energy density of batteries.

To address the aforementioned drawbacks, strenuous efforts have been made towards developing new conductive composite cathode materials, modifying electrolytes, designing multifunctional binders and suppressing the formation of lithium dendrites in anodes. ${ }^{11-13}$ Up to now, rechargeable $\mathrm{Li}-\mathrm{S}$ batteries have made remarkable progress in all directions, but the research fields of electrolytes, binders and anodes are still in infancy. The main strategy for improving electrochemical performance still concentrates on constructing functional cathode architectures. ${ }^{14,15}$ The mainstream of research on sulfur cathodes is divided into two parts: interior modification and external structural design. To date, various materials have been applied to interior modification of cathodes including graphene and its derivatives, ${ }^{16-18}$ metal oxides, ${ }^{19,20}$ porous carbon, ${ }^{21}$ conducting polymers, ${ }^{22}$ and carbon fibers. ${ }^{23}$ These effective tactics are used to physically trap and chemically adsorb sulfur and polysulfide species, resulting in excellent electrochemical performance. In addition, the external structure is fabricated by adding an interlayer between the cathode and separator, such as microporous carbon paper, ${ }^{24}$ porous metal foam,${ }^{25}$ or $\mathrm{TiO}_{2} /$ graphene. ${ }^{26}$ The results demonstrated that the interlayer could effectively 


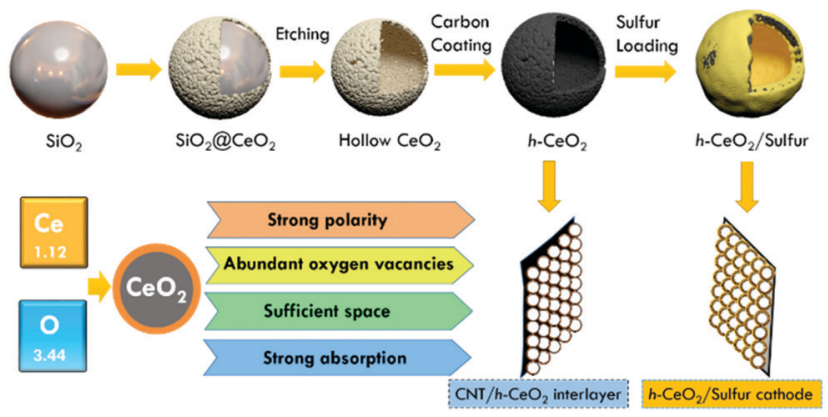

Fig. 1 Illustration of synthetic procedures of a $\mathrm{h}-\mathrm{CeO}_{2} /$ sulfur cathode and a $\mathrm{CNT} / \mathrm{h}-\mathrm{CeO}_{2}$ interlayer for $\mathrm{Li}-\mathrm{S}$ batteries.

suppress the shuttle effect of polysulfides and reutilize the captured active materials.

In general, nonpolar carbon materials absorb sulfur but repel polar polysulfides. Numerous reports have proved that polar metal oxides have strong affinity to polysulfides. ${ }^{27,28}$ The larger the difference in electronegativity between metal and oxygen, the stronger the polarity. Compared to the electronegativities of $\mathrm{Ti}$ (1.54), $\mathrm{Al}$ (1.61), $\mathrm{Mg}$ (1.31), $\mathrm{Mn}$ (1.55), $\mathrm{Zr}$ (1.33) and V (1.63), Ce (1.12) has a larger difference with respect to $\mathrm{O}(3.44)$, indicating a stronger polarity of ceria. Besides, $\mathrm{CeO}_{2}$ exhibits unique properties of rich oxygen vacancies, ${ }^{29}$ high catalytic activity ${ }^{30}$ and strong absorption of lithium polysulfides. ${ }^{31}$ After electrochemical lithiation, its ionic and electronic transport properties could be further improved. ${ }^{32}$ Moreover, building hollow structures has been proved to be an effective strategy to shorten transport length for both ions and electrons. ${ }^{33-38}$ Simultaneously, well-designed electrode structures use simple preparation processes and are beneficial for future commercialization. ${ }^{39-43}$

Based on the above comprehension, in this study, we selected $\mathrm{CeO}_{2}$ hollow spheres to fabricate the inside and outside structures of cathodes (Fig. 1). The sandwich-type architecture contained h- $-\mathrm{CeO}_{2} /$ sulfur and $\mathrm{CNT} / \mathrm{h}-\mathrm{CeO}_{2}$ interlayers, simply by coating the surface of $\mathrm{h}-\mathrm{CeO}_{2} /$ sulfur with a $\mathrm{CNT} / \mathrm{h}-\mathrm{CeO}_{2}$ interlayer. This novel architecture exhibits multifold features: (i) hollow spheres can not only provide a large inner void space for loading sulfur but also tolerate the volume expansion of sulfur during cycling; (ii) strongly polar $\mathrm{CeO}_{2}$ with abundant oxygen vacancies can effectively suppress polysulfide diffusion and accelerate lithium ion transport; (iii) the initial conductivity of $\mathrm{CeO}_{2}$ was improved by coating with a carbon layer, resulting in high transport of electrons; (iv) by introducing the $\mathrm{CNT} / \mathrm{h}-\mathrm{CeO}_{2}$ interlayer, the unique features of $\mathrm{CeO}_{2}$ are fully reused during electrochemical cycling. With these desired properties, a novel $\mathrm{h}-\mathrm{CeO}_{2} /$ sulfur-0.8-CNT/h-CeO ${ }_{2}$ cathode was achieved.

\section{Results and discussion}

Transmission electron microscopy (TEM) and scanning electron microscopy (SEM) were used to analyze the microstructures and components of the as-prepared samples. As shown in Fig. 2a, the $\mathrm{SiO}_{2}$ templates were uniform nanospheres with diameters of about $200 \mathrm{~nm}$. After chemical etching, hollow $\mathrm{CeO}_{2}$ was obtained

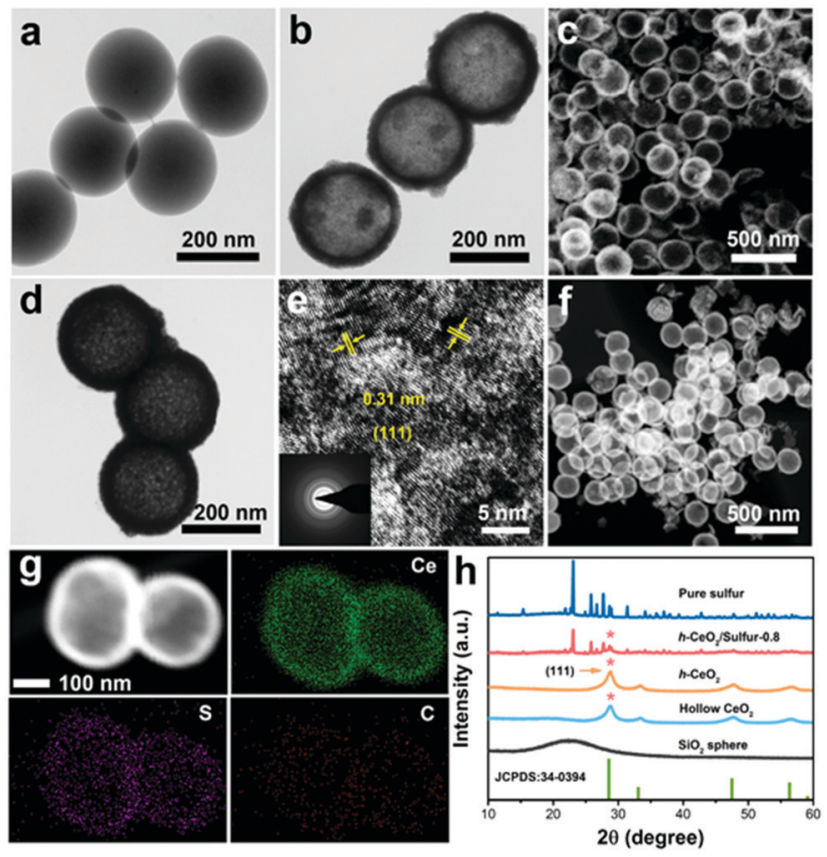

Fig. 2 TEM images of (a) $\mathrm{SiO}_{2}$ and (b) hollow $\mathrm{CeO}_{2}$. (c) $\mathrm{SEM}$ image of hollow $\mathrm{CeO}_{2}$. (d) TEM image and (e) HRTEM image of $\mathrm{h}-\mathrm{CeO}_{2}$ (the inset shows a SAED pattern). (f) HAADF-TEM image and (g) EDS elemental mapping of $\mathrm{h}-\mathrm{CeO}_{2} /$ sulfur-0.8. (h) XRD patterns.

and showed a hollow interior (Fig. $2 \mathrm{~b}$ and c), whose inner diameter was in good accordance with the size of the $\mathrm{SiO}_{2}$ template. Fig. 2 d reveals that carbon was uniformly coated on the surface of hollow $\mathrm{CeO}_{2}$. The BET surface area of h-CeO ${ }_{2}$ was about $47.72 \mathrm{~m}^{2} \mathrm{~g}^{-1}$ (Fig. S1, ESI $\dagger$ ) and a HRTEM image was recorded on the surface of h- $\mathrm{CeO}_{2}$ (Fig. 2e). The measured interplanar spacing of $0.31 \mathrm{~nm}$ was indexed well to the $\mathrm{CeO}_{2}(111)$ plane. The high-angle annular dark-field (HAADF) TEM image (Fig. 2f) and EDS elemental mapping (Fig. 2g) demonstrated the homogeneous distribution of $\mathrm{Ce}, \mathrm{S}$ and $\mathrm{C}$ within $\mathrm{h}-\mathrm{CeO}_{2} /$ sulfur composites. Since electrochemical redox reaction mainly took place at the interface of host materials, the highly uniform dispersion of sulfur at the nanoscale could fully utilize the active and adsorptive sites of $\mathrm{CeO}_{2}$. h- $-\mathrm{CeO}_{2} /$ sulfur- $x$ $(x=0.7,0.8$, and 0.9$)$, where $x$ is the initial weight proportion of sulfur, were prepared by tuning the initial weight ratio between $\mathrm{h}-\mathrm{CeO}_{2}$ and sulfur. The practical weight proportions of sulfur in the $h-\mathrm{CeO}_{2} /$ sulfur- $x$ samples were determined using TGA measurements (Fig. S2, ESI $\dagger$ ). As shown in Fig. $2 \mathrm{~h}$, typical peaks are located at $28.8^{\circ}, 33.4^{\circ}, 47.8^{\circ}$ and $56.6^{\circ}$, corresponding to the (111), (200), (220) and (311) planes of the cubic phase $\left(\mathrm{CeO}_{2}\right.$, JCPDS 34-0394). In addition, the strong peaks at $23.0^{\circ}, 25.8^{\circ}$ and $27.7^{\circ}$ can be indexed to the (222), (026) and (040) planes, respectively, which accorded well with the characteristic diffraction peaks of pure sulfur.

To understand the strong interactions, density functional theory (DFT) calculation was implemented in the Vienna ab initio simulation package (VASP). Fig. 3a and Fig. S3 (ESI $\dagger$ ) show the optimized geometries of $\mathrm{S}_{8}$ and lithium polysulfides adsorbed on the surface of $\mathrm{CeO}_{2}$, respectively. The calculated 
(a)

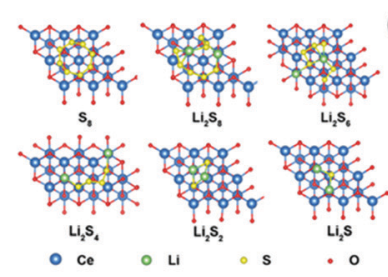

(b)

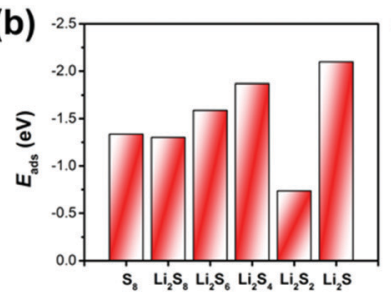

(c)

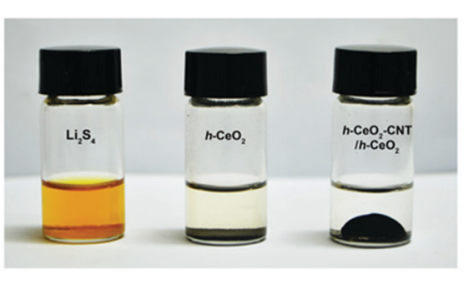

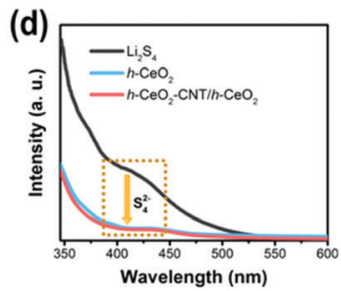
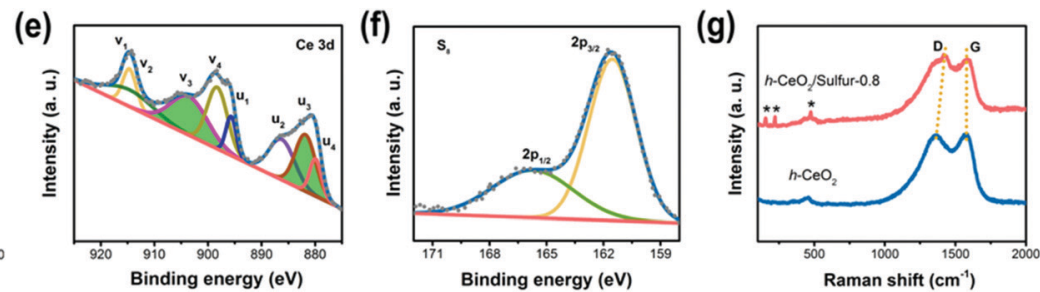

Fig. 3 (a) Optimized geometries and (b) adsorption energies of $\mathrm{S}_{8}$ and polysulfides on ceria surfaces; (c) digital photographs showing the adsorption ability of $\mathrm{Li}_{2} \mathrm{~S}_{4}$ after $12 \mathrm{~h}$; (d) UV/vis absorption spectra of lithium polysulfide $\left(\mathrm{Li}_{2} \mathrm{~S}_{4} / \mathrm{DME}\right)$ solution before and after adding $\mathrm{h}-\mathrm{CeO}_{2}$ and $\mathrm{h}-\mathrm{CeO} \mathrm{O}_{2}-\mathrm{CNT}$ h- $\mathrm{CeO}_{2}$ interlayers; (e) and (f) high-resolution XPS spectra of h- $\mathrm{CeO}_{2} /$ sulfur-0.8; and (g) Raman spectra of h- $\mathrm{CeO}_{2}$ and h-CeO $/$ sulfur-0.8.

adsorption energies (Fig. 3b) were $-1.337 \mathrm{eV}$ for $\mathrm{S}_{8},-1.302 \mathrm{eV}$ for $\mathrm{Li}_{2} \mathrm{~S}_{8},-1.589 \mathrm{eV}$ for $\mathrm{Li}_{2} \mathrm{~S}_{6},-1.870 \mathrm{eV}$ for $\mathrm{Li}_{2} \mathrm{~S}_{4},-0.736 \mathrm{eV}$ for $\mathrm{Li}_{2} \mathrm{~S}_{2}$ and $-2.098 \mathrm{eV}$ for $\mathrm{Li}_{2} \mathrm{~S}$. The calculated values were significantly higher than those for nonpolar carbon materials, ${ }^{44,45}$ suggesting strong binding between $\mathrm{CeO}_{2}$ and polysulfides. The strong binding was conducive to immobilizing lithium polysulfides and preventing them from dissolving into electrolyte, resulting in improved performance of Li-S batteries.

In order to further assess the adsorption ability of h-CeO and $\mathrm{h}-\mathrm{CeO}_{2}-\mathrm{CNT} / \mathrm{h}-\mathrm{CeO}_{2}$ interlayers, polysulfide adsorption measurements and UV/vis absorption tests were performed in $\mathrm{Li}_{2} \mathrm{~S}_{4} /$ DME solutions. As shown in Fig. 3c, the initial $\mathrm{Li}_{2} \mathrm{~S}_{4} / \mathrm{DME}$ solution was transparent orange, and then its color changed from orange to colorless after adding the two samples, respectively. Fig. 3d shows a characteristic absorption region around $420 \mathrm{~nm}$, which could be ascribed to $\mathrm{S}_{4}{ }^{2-}$ species. ${ }^{46}$ It was clearly observed that the peak intensities of the $\mathrm{Li}_{2} \mathrm{~S}_{4}$ solutions with the two samples significantly decreased, indicating the higher affinity to and strong adsorption of $\mathrm{S}_{4}{ }^{2-}$ species. As shown in Fig. 3e, the complex Ce 3d spectra were fitted with eight peaks, labeled $v_{1}$ (914.8), $v_{2}$ (912.5), $v_{3}$ (903.7), $v_{4}$ (898.4), $u_{1}$ (895.7), $u_{2}$ (886.3), $\mathrm{u}_{3}$ (881.8), and $\mathrm{u}_{4}$ (880.0), respectively. The peaks labeled with $v_{3}$ and $u_{3}$ represented the $3 d^{10} 4 f^{1}$ electronic state of $\mathrm{Ce}^{3+}$, and the other peaks $\left(\mathrm{v}_{1}, \mathrm{v}_{2}, \mathrm{v}_{4}, \mathrm{u}_{1}, \mathrm{u}_{2}\right.$ and $\left.\mathrm{u}_{4}\right)$ represented the $3 \mathrm{~d}^{10} 4 \mathrm{f}^{0}$ electronic state of $\mathrm{Ce}^{4+}$. The results revealed both $\mathrm{Ce}^{3+}$ and $\mathrm{Ce}^{4+}$ species in the sample. As is known to all, the presence of $\mathrm{Ce}^{3+}$ ions could lead to charge imbalance, creating oxygen vacancies and unsaturated chemical bonds in the $\mathrm{CeO}_{2}$ lattice, which is dependent on the concentration of $\mathrm{Ce}^{3+}$ ions. ${ }^{47}$ The concentration of $\mathrm{Ce}^{3+}$ ions was estimated from the ratio of the integrated $\mathrm{Ce}^{3+}$ peaks to the sum of the $\mathrm{Ce}^{3+}$ and $\mathrm{Ce}^{4+}$ peaks, as follows: $\rho\left(\mathrm{Ce}^{3+}\right)=\left[A\left(\mathrm{Ce}^{3+}\right)\right] /\left[A\left(\mathrm{Ce}^{3+}\right)+A\left(\mathrm{Ce}^{4+}\right)\right]$.

According to the calculation, the concentration of $\mathrm{Ce}^{3+}$ ions in the $\mathrm{h}-\mathrm{CeO}_{2} /$ sulfur sample was $\sim 0.38$, indicating abundant oxygen vacancy defects. Fig. $3 \mathrm{f}$ shows the $\mathrm{S} 2 \mathrm{p}$ spectrum has two typical peaks at $161.5\left(2 \mathrm{p}_{3 / 2}\right)$ and $165.6\left(2 \mathrm{p}_{1 / 2}\right) \mathrm{eV}$, due to their spin-orbit coupling. Furthermore, the bonding energy of 161.5 $\left(2 \mathrm{p}_{3 / 2}\right) \mathrm{eV}$ was lower than that of elemental sulfur $(163.8 \mathrm{eV})$, which indicated the possible presence of $\mathrm{C}-\mathrm{S}$ or $\mathrm{O}-\mathrm{S}$ species. ${ }^{48}$ They can effectively anchor the polysulfides onto the surface during the electrochemical process. C 1s, O 1s and N 1s spectra are displayed in Fig. S4 (ESI $\dagger$ ). In Fig. $3 g$, the Raman spectra of h- $\mathrm{CeO}_{2}$ and h- $\mathrm{CeO}_{2} /$ sulfur-0.8 displayed typical features of the carbon layer, D and G peaks at 1368 and $1578 \mathrm{~cm}^{-1}$. The high intensity ratio of the $\mathrm{D}$ to $\mathrm{G}$ band $\left(I_{\mathrm{D}} / I_{\mathrm{G}}=0.97\right)$ confirmed the existence of graphitic structure. ${ }^{49}$ The sulfur of the h- $\mathrm{CeO}_{2} /$ sulfur-0.8 composite showed the characteristic peaks at 155.9, 221.7 and $473.4 \mathrm{~cm}^{-1}$, respectively.

The cycling performance and rate capabilities of h-CeO $/$ sulfur- $x$ at $0.2 \mathrm{C}$ are presented in Fig. $4 \mathrm{a}$ and Fig. S5 (ESI $\dagger$ ), respectively. The h-CeO $\mathrm{C}_{2} /$ sulfur- 0.8 cathode exhibited excellent stability and the capacity retention was as high as $92.3 \%$. However, the capacity retentions of h- $\mathrm{CeO}_{2} /$ sulfur-0.7 and h- $-\mathrm{CeO}_{2} /$ sulfur-0.9 were $68.7 \%$ and $57.3 \%$, respectively. For rate capability, the h- $\mathrm{CeO}_{2} /$ sulfur-0. 8 cathode also displayed the best rate capability at each current density. The typical charge/discharge profiles and cyclic voltammograms $(\mathrm{CV})$ of h-CeO ${ }_{2} /$ sulfur- $x(x=0.7,0.8$ and 0.9 ) cathodes in the range of $1.7-2.6 \mathrm{~V} v s . \mathrm{Li} / \mathrm{Li}^{+}$are shown in Fig. S6 (ESI $\dagger)$. With the increase of sulfur content in cathode materials, h- $\mathrm{CeO}_{2} /$ sulfur-0.8 showed almost the same small polarization as h-CeO $/$ sulfur-0.7 and the polarization of h- $\mathrm{CeO}_{2} /$ sulfur-0.9 was extremely remarkable. The charge/discharge profiles of the initial four cycles showed similar features and were well consistent with the $\mathrm{CV}$ curves, respectively. h- $\mathrm{CeO}_{2} /$ sulfur-0.8 exhibited excellent capacity retention and rate capability due to the optimal proportion of sulfur, which fully utilized the redox reaction of sulfur in cathode material. Consequently, the $\mathrm{h}-\mathrm{CeO}_{2} /$ sulfur- 0.8 cathode was chosen to study the effects of different interlayers in cells. Fig. $4 \mathrm{~b}$ shows the cycling capability of the three samples at $0.5 \mathrm{C}$, wherein the h-CeO ${ }_{2} /$ sulfur-0.8-CNT/h- $\mathrm{CeO}_{2}$ interlayer electrode exhibited superior cycling stability to h-CeO ${ }_{2} /$ sulfur-0.8-CNT. In order to 
(a)

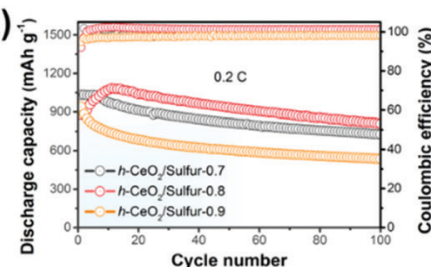

(d)

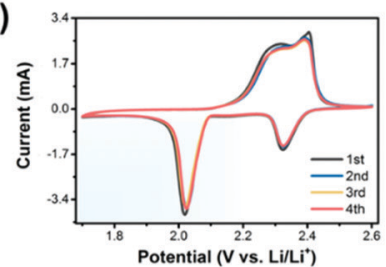

(g)

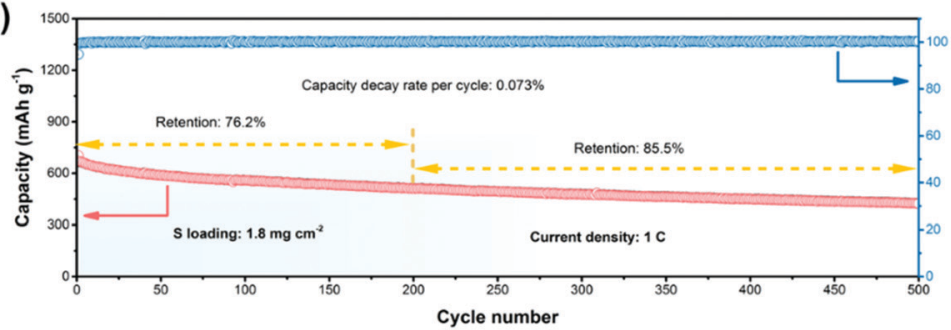

(b)

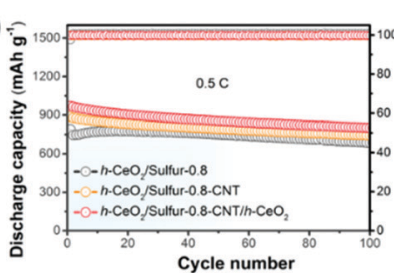

(e)

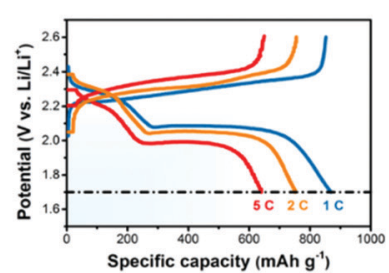

(f)

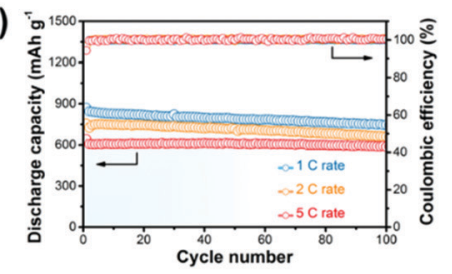

(h)
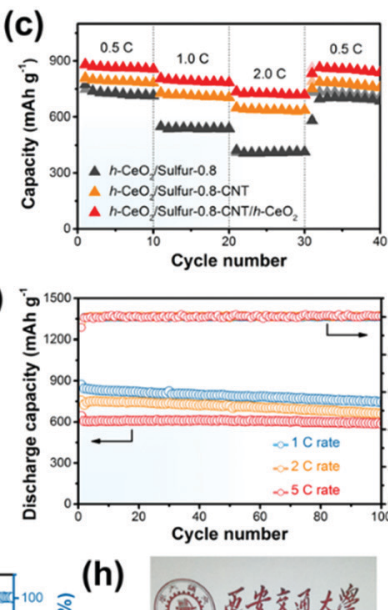

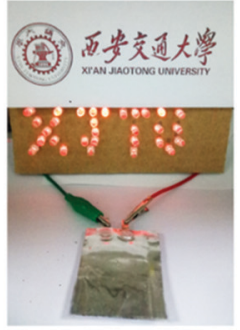

Fig. 4 (a) Cycling performances of $\mathrm{h}-\mathrm{CeO}_{2} /$ sulfur-0.7, $\mathrm{h}-\mathrm{CeO}_{2} /$ sulfur- 0.8 and $\mathrm{h}-\mathrm{CeO}_{2} /$ sulfur -0.9 at $0.2 \mathrm{C}$; (b) cycling performances and (c) rate capabilities of $\mathrm{h}-\mathrm{CeO}_{2} /$ sulfur-0.8, h- $\mathrm{CeO}_{2} /$ sulfur-0.8-CNT and h- $\mathrm{CeO}_{2} /$ sulfur-0.8-CNT/h- $\mathrm{CeO}_{2}$ interlayers; (d) $\mathrm{CV}$ profiles of a h-CeO $/$ sulfur-0.8$\mathrm{CNT} / \mathrm{h}-\mathrm{CeO}_{2}$ interlayer at a scan rate of $0.2 \mathrm{mV} \mathrm{s}^{-1}$; (e) voltage profiles; (f) discharge capacities and coulombic efficiencies at various current densities; (g) long-term cycling properties at $1 \mathrm{C}$ for 500 cycles and (h) a soft-packaged Li-S battery with the $\mathrm{h}-\mathrm{CeO}_{2} / \mathrm{sulfur}-0.8-\mathrm{CNT} / \mathrm{h}-\mathrm{CeO}{ }_{2}$ interlayer electrode.

demonstrate the rate performance of the three samples, the current density was changed from 0.5 to $2.0 \mathrm{C}$, as shown in Fig. 4c. The h- $\mathrm{CeO}_{2} /$ sulfur-0.8-CNT/h-CeO 2 electrode displayed discharge capacities of 884,808 and $736 \mathrm{~mA} \mathrm{~h} \mathrm{~g}^{-1}$ at $0.5,1.0$, and $2.0 \mathrm{C}$, respectively. Compared with $\mathrm{h}-\mathrm{CeO}_{2} /$ sulfur- 0.8 and h-CeO $2 /$ sulfur-0.8-CNT, h- $-\mathrm{CeO}_{2} /$ sulfur-0.8-CNT/h-CeO ${ }_{2}$ showed the best rate capability, due to the synergistic effect of CNTs and $\mathrm{CeO}_{2}$ hollow spheres. CNTs boosted electronic conductivity and $\mathrm{CeO}_{2}$ hollow spheres led to higher chemisorption and physical confinement to sulfur species. The volumetric capacities of the $\mathrm{h}-\mathrm{CeO}_{2} /$ sulfur- 0.8 and $\mathrm{h}-\mathrm{CeO}_{2} /$ sulfur-0.8-CNT/ h- $\mathrm{CeO}_{2}$ cathodes at $0.5 \mathrm{C}$ are shown in Fig. $\mathrm{S} 7$ (ESI $\dagger$ ). The $\mathrm{CV}$ curves of the $\mathrm{h}-\mathrm{CeO}_{2} /$ sulfur- $0.8-\mathrm{CNT} / \mathrm{h}-\mathrm{CeO}_{2}$ cathode for the first four cycles were obtained at a scan rate of $0.2 \mathrm{mV} \mathrm{s}^{-1}$. Two distinctive reduction peaks at 2.32 and $2.02 \mathrm{~V}$ are observed in Fig. $4 \mathrm{~d}$. The broad reduction peak at $2.32 \mathrm{~V}$ can be attributed to the reduction of elemental sulfur to intermediate polysulfides $\left(\mathrm{Li}_{2} \mathrm{~S}_{x}, 4 \leq x \leq 8\right)$, while the second reduction peak at $2.02 \mathrm{~V}$ can be ascribed to the further reduction to short-chain insoluble $\mathrm{Li}_{2} \mathrm{~S} / \mathrm{Li}_{2} \mathrm{~S}_{2}$. A strong and broad oxidation peak centered at $2.39 \mathrm{~V}$ corresponded to the reverse processes from $\mathrm{Li}_{2} \mathrm{~S} / \mathrm{Li}_{2} \mathrm{~S}_{2}$ to $\mathrm{Li}_{2} \mathrm{~S}_{x}$ and eventually to $\mathrm{S}_{8}$. In addition, the CV curves of $\mathrm{h}-\mathrm{CeO}_{2} /$ sulfur- 0.8 and $\mathrm{h}-\mathrm{CeO}_{2} /$ sulfur-0.8-CNT were also recorded (Fig. S6c and S8, ESI $\dagger$ ). Moreover, comparing both curves, we found that the subsequent cycles of $\mathrm{h}-\mathrm{CeO}_{2} /$ sulfur- $0.8-\mathrm{CNT} / \mathrm{h}-\mathrm{CeO}_{2}$ nearly overlapped each other, implying a minimal polarization and good electrochemical stability. The electrochemical impedance spectroscopy (EIS) measurements were carried out for three fresh cathodes (Fig. S9, ESI $\dagger$ ). The Nyquist plots were composed of two semicircles and a slope line. The EIS fitting results (Table S1, ESI $\dagger$ ) showed that the three curves exhibited slight change in the high and low frequency ranges, suggesting similar charge transfer resistances and Warburg impedances.

Fig. $4 \mathrm{e}$ exhibits the charge/discharge profiles of the $\mathrm{h}-\mathrm{CeO}_{2} /$ sulfur-0.8-CNT/h- $-\mathrm{CeO}_{2}$ cathode at various rates. All of them displayed two well-defined plateaus in accordance with the CV results. At $1 \mathrm{C}, 2 \mathrm{C}$ and $5 \mathrm{C}$ rates, the $\mathrm{h}-\mathrm{CeO}_{2} /$ sulfur-0.8-CNT/ $\mathrm{h}-\mathrm{CeO}_{2}$ cathode still showed excellent cycling performance and high coulombic efficiencies above 99\% except for the first cycle (Fig. 4f). Their initial capacities were 876, 761, and $644 \mathrm{~mA} \mathrm{~h} \mathrm{~g}^{-1}$ and the capacity retentions were $85.7 \%, 87.8 \%$, and 92.4\% after 100 cycles, respectively. The results better showed the advantage of the functional cathode architecture with $\mathrm{CeO}_{2}$ hollow spheres in Li-S batteries. Compared with previously reported studies on metal oxides (Table $\mathrm{S} 2, \mathrm{ESI} \dagger$ ), the $\mathrm{h}-\mathrm{CeO}_{2} /$ sulfur-0.8-CNT/h-CeO ${ }_{2}$ cathode showed higher rate capability and better cycling stability. In order to further demonstrate its superiority, a long-term cycle test with a sulfur loading of $1.8 \mathrm{mg} \mathrm{cm}^{-2}$ was carried out at a rate of $1 \mathrm{C}$. As shown in Fig. $4 \mathrm{~g}$, the cathode maintained a capacity of $511 \mathrm{~mA} \mathrm{~h} \mathrm{~g}{ }^{-1}$ and achieved a capacity retention of $76.2 \%$ in the 200th cycle. Then, the capacity rentention was $85.5 \%$ from the 200th to 500th cycle. More importantly, the capacity decay rate of $0.073 \%$ per cycle was very small during the 500 cycles, representing little shuttle effect of polysulfides.

As a proof-of-concept demonstration, a soft-packaged Li-S battery was assembled with the h- $-\mathrm{CeO}_{2} /$ sulfur- $0.8-\mathrm{CNT} / \mathrm{h}-\mathrm{CeO}_{2}$ as the cathode. The charge and discharge capacities of the battery are shown in Fig. S10 (ESI $\dagger$ ). As shown in Fig. 4h, the 


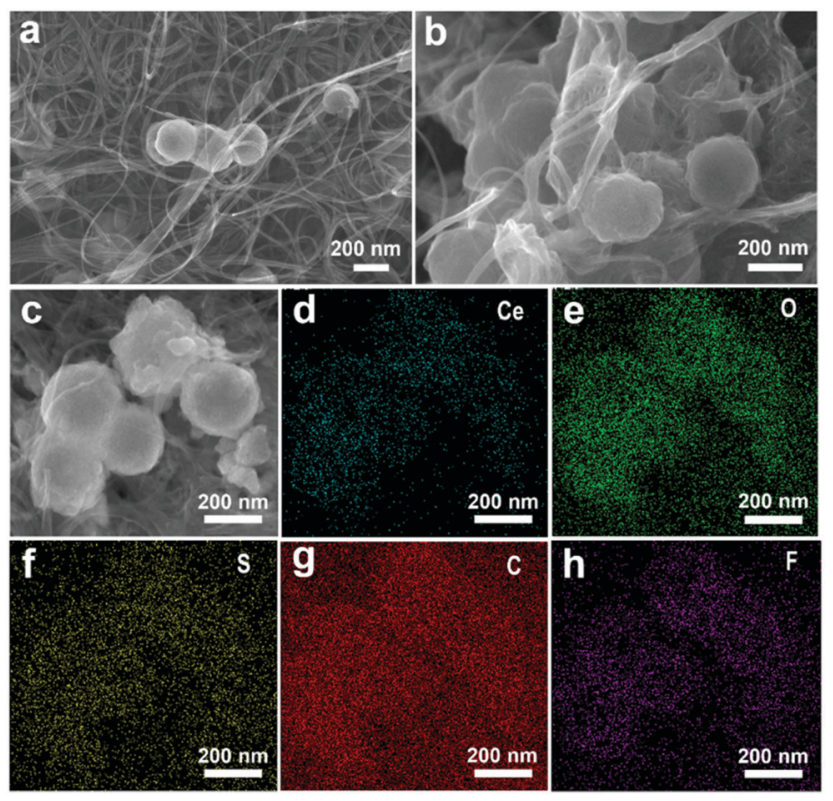

Fig. 5 (a) Initial CNT/h- $\mathrm{CeO}_{2}$ interlayer; (b) $\mathrm{CNT} / \mathrm{h}-\mathrm{CeO}_{2}$ interlayer after 500 cycles; and $(c-h)$ the images of SEM and EDX elemental mapping.

soft-packaged battery could light up a visual XJTU model, which was made up of 30 red light-emitting diodes.

To better understand its excellent electrochemical performance, SEM images of the $\mathrm{CNT} / \mathrm{h}-\mathrm{CeO}_{2}$ interlayer were compared before and after 500 cycles (Fig. $5 \mathrm{a}$ and b). In the pristine $\mathrm{CNT} / \mathrm{h}-\mathrm{CeO}_{2}$ interlayer, h- $\mathrm{CeO}_{2}$ nanoparticles were uniformly embedded in the upper, middle and lower positions of the layer structure. After 500 cycles, although the hollow spherical structure was still maintained, the glue-like morphology indicated that the dissolved polysulfides were mainly absorbed by polar $\mathrm{CeO}_{2}$ in the interlayer. The elemental mapping results after cycling are shown in Fig. $5 \mathrm{c}-\mathrm{h}$, and the sulfur signal was also intensively distributed over and around $\mathrm{CeO}_{2}$, proving good adsorption on sulfur species and ensuring superior reutilization and reversibility. It was clearly observed that the carbon signal was stronger than the cerium and oxygen signals, implying good conductivity even for long cycles. The mapping image of fluorine confirmed that an effective barrier was developed in fluorinated electrolyte, which could mitigate polysulfide transport and allowed lithium ion transport. ${ }^{50}$ All the above results further demonstrated that the $\mathrm{CeO}_{2}$-containing interlayer in this cell architecture was very important to mitigate the shuttling effect and improve the cycling stability. To elaborate the advantages of functional cathode architecture, a schematic illustration of $\mathrm{Li}-\mathrm{S}$ batteries is shown in Fig. S11 (ESI $\dagger$ ). The results demonstrated that this architecture could further efficiently intercept the migrating polysulfides and reutilize the trapped active material, leading to a better electrochemical performance.

\section{Conclusions}

In summary, a multifunctional h- $\mathrm{CeO}_{2} /$ sulfur- $x$-CNT/h-CeO ${ }_{2}$ cathode was designed and synthesized by a simple layer-by-layer procedure. The functional cathode architecture with $\mathrm{CeO}_{2}$ benefits from strong physical adsorption and chemical binding with the lithium polysulfides, and also well tolerates volumetric expansion of sulfur upon lithiation. More importantly, this architecture could make full use of the unique features of $\mathrm{CeO}_{2}$ and reutilize the active materials during electrochemical cycling. The h-CeO $/$ sulfur-0.8-CNT/h- $\mathrm{CeO}_{2}$ cathode showed high rate capability and long-term cycling stability of 500 cycles with a low capacity decay of $0.073 \%$ at $1 \mathrm{C}$. We believe that this study may offer an instructive strategy of rational structural construction for advanced Li-S battery cathodes.

\section{Conflicts of interest}

There are no conflicts to declare.

\section{Acknowledgements}

We gratefully acknowledge the support from the China National Funds for Excellent Young Scientists (21522106) and the National Key R\&D Program of China (2017YFA0208000). We also acknowledge Prof. Chunhua Yan for his kind support and suggestions.

\section{Notes and references}

1 A. Manthiram, Y. Fu, S.-H. Chung, C. Zu and Y.-S. Su, Chem. Rev., 2014, 114, 11751-11787.

2 J. Y. Hwang, H. M. Kim, S. K. Lee, J. H. Lee, A. Abouimrane, M. A. Khaleel, I. Belharouak, A. Manthiram and Y. K. Sun, Adv. Energy Mater., 2016, 6, 1501480.

3 S. Evers and L. F. Nazar, Acc. Chem. Res., 2013, 46, 1135-1143.

4 S. H. Chung, C. H. Chang and A. Manthiram, Adv. Funct. Mater., 2018, 1801188.

5 L. Hu, C. Dai, H. Liu, Y. Li, B. Shen, Y. Chen, S. J. Bao and M. Xu, Adv. Energy Mater., 2018, 1800709.

6 Y. S. Su and A. Manthiram, Chem. Commun., 2012, 48, 8817-8819.

7 M. Wild, L. O'neill, T. Zhang, R. Purkayastha, G. Minton, M. Marinescu and G. Offer, Energy Environ. Sci., 2015, 8, 3477-3494.

8 S. Xin, L. Gu, N. H. Zhao, Y. X. Yin, L. J. Zhou, Y. G. Guo and L. J. Wan, J. Am. Chem. Soc., 2012, 134, 18510-18513.

9 R. Fang, S. Zhao, Z. Sun, D. W. Wang, H. M. Cheng and F. Li, Adv. Mater., 2017, 29, 1606823.

10 M. K. Song, Y. Zhang and E. J. Cairns, Nano Lett., 2013, 13, 5891-5899.

11 E. Cha, M. D. Patel, J. Park, J. Hwang, V. Prasad, K. Cho and W. Choi, Nat. Nanotechnol., 2018, 13, 337-344.

12 L. Fan, S. Chen, J. Zhu, R. Ma, S. Li, R. Podila, A. M. Rao, G. Yang, C. Wang, Q. Liu, Z. Xu, L. Yuan, Y. Huang and B. Lu, Adv. Sci., 2018, 5, 1700934.

13 L. Ma, R. Chen, G. Zhu, Y. Hu, Y. Wang, T. Chen, J. Liu and Z. Jin, ACS Nano, 2017, 11, 7274-7283. 
14 Q. Pang, X. Liang, C. Y. Kwok and L. F. Nazar, Nat. Energy, 2016, 1, 16132.

15 W. Kong, L. Yan, Y. Luo, D. Wang, K. Jiang, Q. Li, S. Fan and J. Wang, Adv. Funct. Mater., 2017, 27, 1606663.

16 W. Wu, J. Pu, J. Wang, Z. Shen, H. Tang, Z. Deng, X. Tao, F. Pan and H. Zhang, Adv. Energy Mater., 2018, 8, 1702373.

17 Z. Zhang, L. L. Kong, S. Liu, G. R. Li and X. P. Gao, Adv. Energy Mater., 2017, 7, 1602543.

18 Z. Li, Y. Jiang, L. Yuan, Z. Yi, C. Wu, Y. Liu, P. Strasser and Y. Huang, ACS Nano, 2014, 8, 9295-9303.

19 Z. Wei Seh, W. Li, J. J. Cha, G. Zheng, Y. Yang, M. T. McDowell, P. C. Hsu and Y. Cui, Nat. Commun., 2013, 4, 1331.

20 D. Xiao, C. Lu, C. Chen and S. Yuan, Energy Storage Mater., 2018, 10, 216-222.

21 G. Li, J. Sun, W. Hou, S. Jiang, Y. Huang and J. Geng, Nat. Commun., 2016, 7, 10601.

22 A. G. Simmonds, J. J. Griebel, J. Park, K. R. Kim, W. J. Chung, V. P. Oleshko, J. Kim, E. T. Kim, R. S. Glass, C. L. Soles, Y. E. Sung, K. Char and J. Pyun, ACS Macro Lett., 2014, 3, 229-232.

23 H. Wang, C. Zhang, Z. Chen, H. K. Liu and Z. Guo, Carbon, 2015, 81, 782-787.

24 Y. S. Su and A. Manthiram, Nat. Commun., 2012, 3, 1166.

$25 \mathrm{X}$. Li, S. Chen, J. Fan, Z. Hu and S. Zhang, Ind. Eng. Chem. Res., 2018, 57, 4880-4886.

26 Z. Xiao, Z. Yang, L. Wang, H. Nie, M. Zhong, Q. Lai, X. Xu, L. Zhang and S. Huang, Adv. Mater., 2015, 27, 2891-2898.

27 X. Liu, J. Q. Huang, Q. Zhang and L. Mai, Adv. Mater., 2017, 29, 1601759.

28 G. Zhou, Y. Zhao, C. Zu and A. Manthiram, Nano Energy, 2015, 12, 240-249.

29 L. Lv, D. Zha, Y. Ruan, Z. Li, X. Ao, J. Zheng, J. Jiang, H. M. Chen, W. H. Chiang, J. Chen and C. Wang, ACS Nano, 2018, 12, 3042-3051.

30 Z. Liu, J. Zhu, J. Li, L. Ma and S. I. Woo, ACS Appl. Mater. Interfaces, 2014, 6, 14500-14508.

31 X. Tao, J. Wang, C. Liu, H. Wang, H. Yao, G. Zheng, Z. W. Seh, Q. Cai, W. Li, G. Zhou, C. Zu and Y. Cui, Nat. Commun., 2016, 7, 11203.

32 K. Li, X. Zhou, A. Nie, S. Sun, Y. B. He, W. Ren, B. Li, F. Kang, J. K. Kim and T. Y. Zhang, Nano Lett., 2017, 17, 1282-1288.
33 J. Wang, H. Tang, L. Zhang, H. Ren, R. Yu, Q. Jin, J. Qi, D. Mao, M. Yang, Y. Wang, P. Liu, Y. Zhang, Y. Wen, L. Gu, G. Ma, Z. Su, Z. Tang, H. Zhao and D. Wang, Nat. Energy, 2016, 1, 16050.

34 F. Wang, J. Wang, H. Ren, H. Tang, R. Yu and D. Wang, Inorg. Chem. Front., 2016, 3, 365-369.

35 J. Wang, H. Tang, H. Wang, R. Yu and D. Wang, Mater. Chem. Front., 2017, 1, 414-430.

36 X. Zhao, J. Wang, R. Yu and D. Wang, J. Am. Chem. Soc., 2018, 140, 17114-17119.

37 H. Ren, R. Yu, J. Wang, Q. Jin, M. Yang, D. Mao, D. Kisailus, H. Zhao and D. Wang, Nano Lett., 2014, 14, 6679-6684.

38 S. Xu, C. M. Hessel, H. Ren, R. Yu, Q. Jin, M. Yang, H. Zhao and D. Wang, Energy Environ. Sci., 2014, 7, 632-637.

39 J. Qi, X. Lai, J. Wang, H. Tang, H. Ren, Y. Yang, Q. Jin, L. Zhang, R. Yu, G. Ma, Z. Su, H. Zhao and D. Wang, Chem. Soc. Rev., 2015, 44, 6749-6773.

40 J. Wang, Y. Cui and D. Wang, Adv. Mater., 2018, 1801993.

41 J. Wang, L. Liao, Y. Li, J. Zhao, F. Shi, K. Yan, A. Pei, G. Chen, G. Li, Z. Lu and Y. Cui, Nano Lett., 2018, 18, 7060-7065.

42 D. Mao, J. Wan, J. Wang and D. Wang, Adv. Mater., 2018, 1802874.

43 J. Wang, N. Yang, H. Tang, Z. Dong, Q. Jin, M. Yang, D. Kisailus, H. Zhao, Z. Tang and D. Wang, Angew. Chem., Int. Ed., 2013, 52, 6417-6420.

44 C. Zheng, S. Niu, W. Lv, G. Zhou, J. Li, S. Fan, Y. Deng, Z. Pan, B. Li, F. Kang and Q. H. Yang, Nano Energy, 2017, 33, 306-312.

45 G. Li, X. Wang, M. H. Seo, M. Li, L. Ma, Y. Yuan, T. Wu, A. Yu, S. Wang, J. Lu and Z. Chen, Nat. Commun., 2018, 9, 705.

46 C. Barchasz, F. Molton, C. Duboc, J.-C. Leprêtre, S. Patoux and F. Alloin, Anal. Chem., 2012, 84, 3973-3980.

47 S. Putla, M. H. Amin, B. M. Reddy, A. Nafady, K. A. Al Farhan and S. K. Bhargava, ACS Appl. Mater. Interfaces, 2015, 7, 16525-16535.

48 K. Mi, S. Chen, B. Xi, S. Kai, Y. Jiang, J. Feng, Y. Qian and S. Xiong, Adv. Funct. Mater., 2017, 27, 1604265.

49 G. Li, W. Lei, D. Luo, Y. Deng, Z. Deng, D. Wang, A. Yu and Z. Chen, Energy Environ. Sci., 2018, 11, 2372-2381.

50 G. Xu, A. Kushima, J. Yuan, H. Dou, W. Xue, X. Zhang, X. Yan and J. Li, Energy Environ. Sci., 2017, 10, 2544-2551. 